\title{
The Japan Beyond-Brittle Project
}

\author{
H. Muraoka ${ }^{1}$, H. Asanuma ${ }^{2}$, N. Tsuchiya ${ }^{3}$, T. Ito ${ }^{4}$, T. Mogi $^{5}$, H. Ito ${ }^{6}$, and the participants of the \\ ICDP/JBBP Workshop \\ ${ }^{1}$ North Japan Research Institute for Sustainable Energy, Hirosaki University, Matsubara 2-1-3, \\ Aomori 030-0813, Japan \\ ${ }^{2}$ Renewable Energy Research Center, AIST, Central 7, 1-1-1 Higashi, Tsukuba, Ibaraki 305-8567, Japan \\ ${ }^{3}$ Graduate School of Environmental Studies, Tohoku University, Aoba 6-6-20, Miyagi 980-8579, Japan \\ ${ }^{4}$ Institute of Fluid Science, Tohoku University, Katahira 2-1-1, Aoba-ku, Sendai 980-8577, Japan \\ ${ }^{5}$ Graduate School of Sciences, Hokkaido University, Kita 10, Nishi 8, Kita-ku, Sapporo 060-0810, Japan \\ ${ }^{6}$ Independent scientist, Japan
}

Correspondence to: H. Asanuma (h.asanuma@aist.go.jp)

Received: 12 August 2013 - Revised: 7 December 2013 - Accepted: 16 December 2013 - Published: 29 April 2014

\section{Introduction}

\subsection{Outline of the workshop}

The international workshop "Japan Beyond-Brittle Project, JBBP - Scientific drilling to demonstrate the feasibility of engineered geothermal systems in ductile zones" was held at the Graduate School of Engineering, Tohoku University, Sendai, Japan, during 12-16 March 2013. The workshop was cosponsored by the ICDP (International Continental Scientific Drilling Program) and Tohoku University GCOE (Global Center Of Excellence) Project. A total of 102 people attended the workshop and 98 presentations were made (75 oral, 23 poster).

\subsection{Background}

Although various advantages of geothermal energy have been widely accepted, power generation using natural hydrothermal reservoirs has not been recognized in Japan as an attractive investment, mainly because of a general perception of high development risks and uncertain returns on investment.

An engineered geothermal system (EGS) is considered to be the best solution to the problems of the hydrothermal resources. However, previous Japanese hot dry rock (HDR) projects showed that water recovery from an EGS reservoir in a fracture-rich tectonic belt in Japan is at best $50 \%$ (Tenma et al., 2004; Kaieda et al., 2005). Another important issue is the difficulty of designing EGS reservoirs in a tectonic- belt setting, where local variations in tectonic stress and fracture distribution are common. Furthermore, the occurrence of felt earthquakes from the EGS reservoirs (Majer et al., 2007; Häring et al., 2008) introduces additional environmental burdens and risks.

These problems in the development of hydrothermal and EGS reservoirs cannot be readily solved in Japan because they are intrinsically related to the physical characteristics and tectonic setting of the brittle rock mass. Hence,we initiated a project, the Japan Beyond-Brittle Project (JBBP), to investigate the feasibility of developing an EGS in brittleductile transition (BDT) zone. The expected advantages of EGS in the BDT are as follows:

1. More homogeneous rock properties and stress states in the BDT make it conceptually simpler to design and control geothermal reservoirs.

2. A nearly full recovery of injected water can be expected from hydraulically closed reservoirs.

3. Sustainable production can be realized by controlling the flow rate and chemical contents of circulated liquids.

4. Possible site-independent characteristics of ductile zones may lead to the establishment of universal design/development/control methodologies.

5. Induced/triggered earthquakes with damaging magnitudes will not occur in reservoirs in ductile rock masses. 


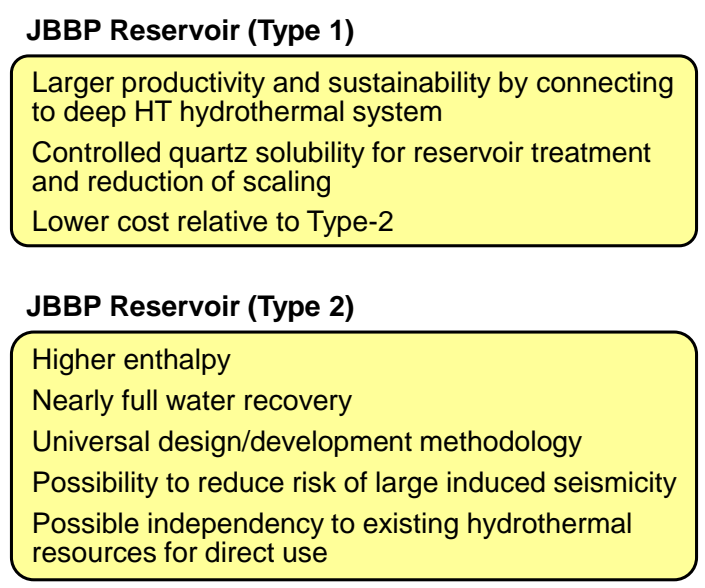

Figure 1. Two possible types of JBBP reservoirs.

\section{Possible reservoir types for JBBP}

It has concluded that there are two end-member reservoir models that should be considered (Fig. 1).

1. A JBBP type 1 reservoir would be created near the top of the BDT, where quartz solubility and fracture density are markedly different from those in the brittle zone. The reservoir should be connected to preexisting hydrothermal systems to increase productivity and provide sustainability.

2. A JBBP type 2 reservoir would be hydraulically or thermally created beyond the BDT, where preexisting fractures are less permeable, and would be hydraulically isolated from the hydrothermal system.

\section{Characterization of the beyond-brittle rock mass}

\subsection{Current understanding of the characteristics of the beyond-brittle rock mass}

The large strain rate by fluid injection renders the rock mass brittle because it fractures in tensile and shear modes, creating fractures aligned with the regional stress regime. These fractures are observed as millimeter- to centimeterscale quartz veins in porphyry copper deposits, which are quartz-filled and plugged fractures, where quartz appears to have precipitated upon adiabatic decompression and cooling as fluids traversed from lithostatic pressure, $P(1)$, to hydrostatic pressure, $P(\mathrm{~h})$, regimes. According to the experimental findings of Okamoto, Tsuchiya, and Saishu in the Tohoku University team, quartz precipitation at temperatures exceed-

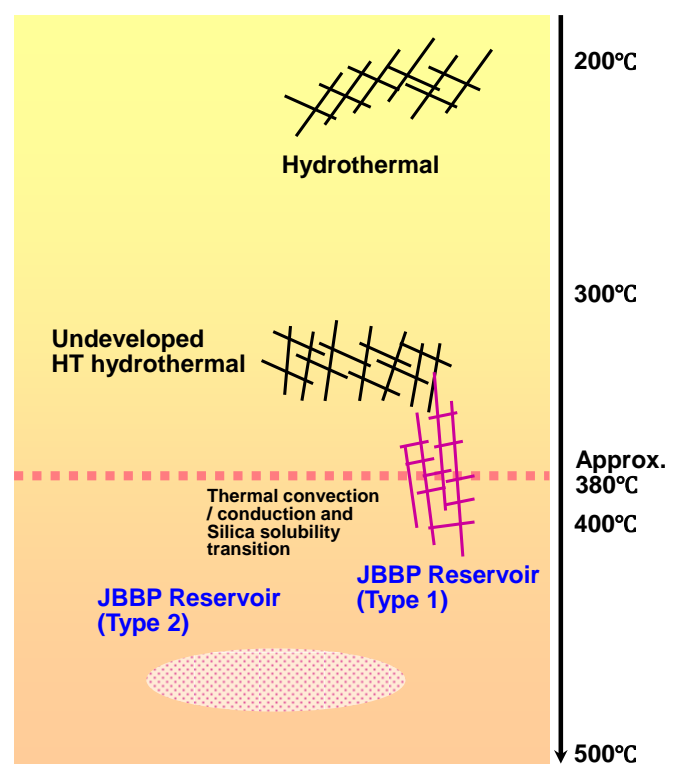

ing $400^{\circ} \mathrm{C}$ seals permeability, possibly on a time scale as short as days or weeks.

The review above suggests that heat extraction from a 400 to $450{ }^{\circ} \mathrm{C}$ granite mass by hydrostatically pressured fluid injection will be challenging, especially because of fracture plugging by quartz and probably also because of closing of fractures by rock creep. Quartz fracture plugging can possibly be limited by high flow rates as fluid temperature descends to below $400^{\circ} \mathrm{C}$ upon adiabatic decompression to $P<P(\mathrm{~h})$. Quartz precipitation rates may slow sufficiently at $T<400{ }^{\circ} \mathrm{C}$ to allow fluid ascent without the plugging of fractures. If not, there is a serious problem that requires investigation.

Rock physics experiments at high pressures and temperatures are central to the achievement of sustainable geothermal development. Characterization of the physical properties of rocks (e.g., permeability, $P$ and $S$ wave velocities, and electrical conductivity), is a strong indicator of the correct interpretation of the geophysical field data used for subsurface exploration.

Workshop participants suggested that laboratory-based physical investigations of the JBBP rock-fluid system should focus on fracture generation and the lifetime of fracture networks in ductile rock systems. Such studies will prove indispensable information for characterizing time and distance scales for fluid flow in ductile rocks and will also provide data that can be used to improve stimulation techniques in connection with new concepts of EGS beyond the brittle field. 


\subsection{Scientific challenges}

Numerical simulation is an important technique that can be applied to assist in the realization of hydrothermal fluid flow in the beyond-brittle rock mass. Recent advances in numerical simulation techniques allow simulation of fully transient single- and multi-phase hydrothermal fluid flow on a continuum extending to magmatic conditions (Hayba and Igebritsen, 1997; Coumou et al., 2008a, b; Weis et al., 2012). These simulations successfully reproduced a wide range of the key features of such systems (e.g., thermal structure and evolution, temporal and spatial patterns of fluid phase states, fluid pressure distribution).

A new approach to the characterization of deep rock masses may arise from the exchange of data and results. For example, in the new Swiss-Icelandic combined hydrological, geochemical and geophysical modeling of geothermal systems (COTHERM) project led by Thomas Driesner (Federal Institute of Technology, Switzerland), the capability of new simulation techniques to accurately predict the distribution of strongly varying fluid properties in the subsurface will be used to better calibrate interpretations of geophysical and geochemical signals. A similar technique could also be used in our project.

In the Kakkonda geothermal field (Japan), a geothermal drill hole (WD-1a; Fig. 2) penetrates the boundary between the hydrothermal-convection and heat-conduction zones (Doi et al., 1998); this is a unique example of drilling beyond the brittle rock mass. Drilling has shown that quartz solubility has a local minimum at $\sim 3100 \mathrm{~m}$ depth $\left(380^{\circ} \mathrm{C}\right.$, $24 \mathrm{MPa}$ ), which is consistent with the depth of the hydrological boundary. Quartz precipitation has possibly created an impermeable siliceous layer at this depth. This water-rock interaction would lead to spontaneous development of the bottom of the hydrothermal-convection zone, which controls fluid flow.

In geothermal fields, we need to consider a coupled chemical and mechanical model to evaluate beyond-brittle geothermal reservoirs.

\section{Creation and control of EGS reservoirs in the ductile zone}

Although we know very little about the geometry of artificial or natural fracture systems in the BDT, we can speculate on the basis of two end-member scenarios. On one hand, hydraulic stimulation may produce a single fracture, or a zone of fracture deformation controlled by local stresses. On the other hand, a more complex cloudlike fracture network might be produced, where the geometry of the fracture system would depend on many factors. These could include deformation mechanisms, stresses, and rock properties. The natural systems of fluid flow can indicate the growth of such a fracture network, as shown by the movement of fluids or changes of pore pressure during and after stimulation. It is also possible that hydraulic fracturing could inadvertently trigger fault motion. Thus, it is very important to understand the mechanical characteristics of faults or fractures.

Our workshop discussions of the creation and maintenance of EGS reservoirs in the BDT and ductile zone were based on current knowledge, especially from the view point of rock mechanics. The subjects specified at the workshop as being of prime importance are (1) mechanical and hydraulic properties of rock, (2) in situ states of stress, and (3) seismic activity on fractures or faults.

\subsection{Mechanical and hydraulic properties of rock}

The creation and maintenance of such an embrittled zone embedded within a nominally ductile region in the deep crust poses significant scientific challenges. The first challenge is to understand how deformation, in the form of either tensile or shear fractures, can be nucleated in a matrix that will deform anelastically by, for example, cataclastic flow. The viscoelastic rheology and failure in such a transitional regime would likely involve a combination of semi-brittle mechanisms, including crystal plasticity, diffusive mass transfer, and microcracking. To formulate modeling methodology, it is advisable to take into account recent advances in the modeling of analogous geodynamic processes, such as stress relaxation during interseismic phases of the earthquake cycle.

It is of considerable importance to address coupled thermo-hydro-mechano-chemo (THMC) processes when considering the effective extraction of energy from geothermal reservoirs. Under high pressure and temperature conditions, chemical reactions such as mineral dissolution and precipitation are very active, and may quickly change the mechanical and hydraulic properties of host rocks. Therefore, the effects of the dissolution and precipitation kinetics on the physical properties of rocks should be examined microscopically.

\subsection{In situ state of stress}

Knowledge of the in situ state of stress and the geometry and hydrologic properties of potential failure surfaces (fractures, faults, and foliation) is required in order to create an EGS reservoir with optimal geometry, fracture density, and heatextraction efficiency.

The magnitude of the least horizontal principal stress (SHmin) is best determined using small-scale hydraulic fracturing stress tests (minifracs). Owing to the difficulty of finding reliable open-hole packers for use at high temperatures, such tests are best carried out in geothermal wells by drilling a short ( $\sim 20 \mathrm{~m}$ long) pilot hole from the bottom of cemented casing and pressurizing the cased hole to carry out a minifrac in the pilot hole. Ideally, minifracs would be conducted below every casing shoe during the drilling of a JBBP borehole, thus obtaining as complete a vertical stress profile as possible. 


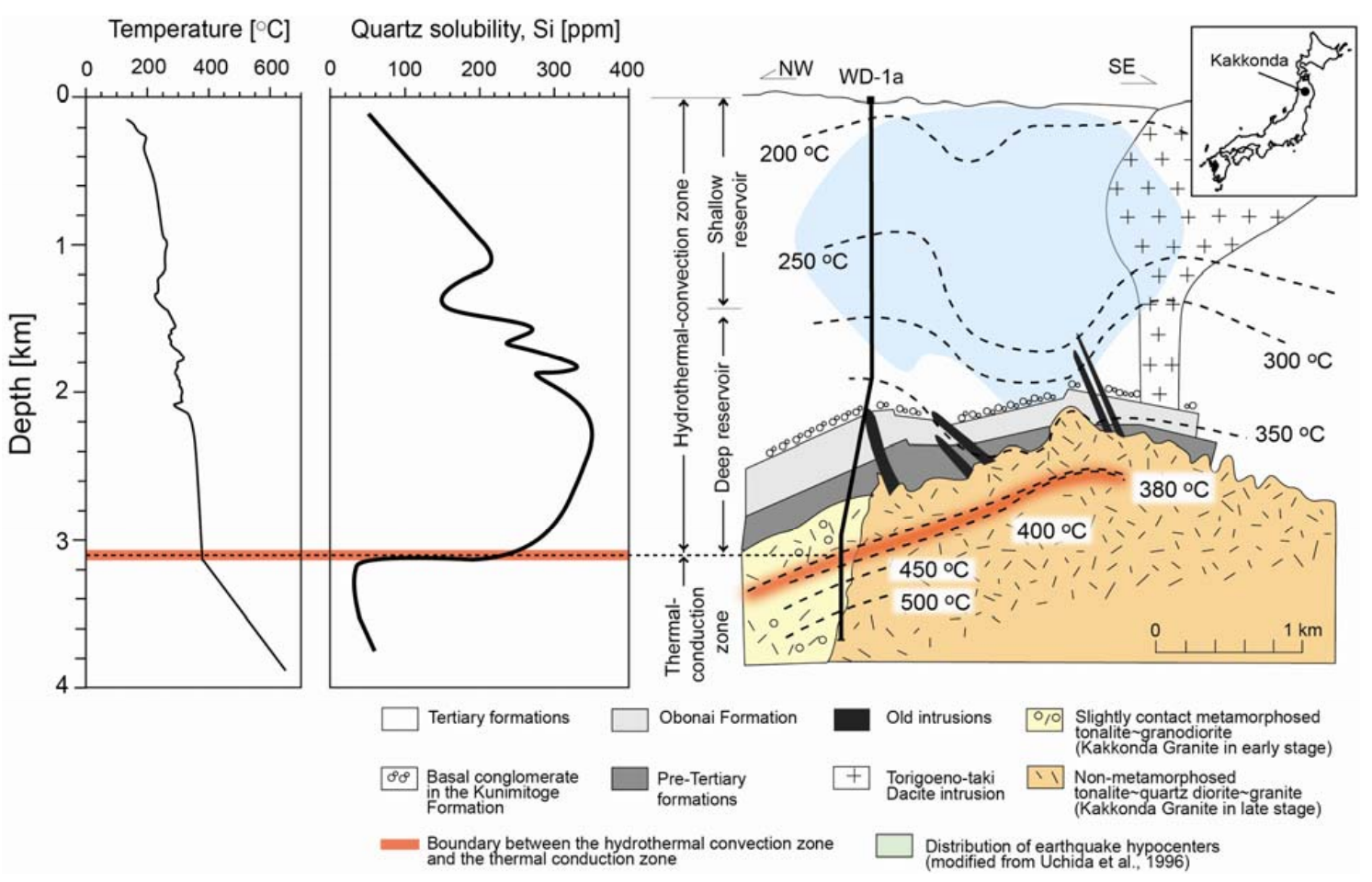

Figure 2. Location of the Kakkonda geothermal field in the Hachimantai volcanic field, northeastern Japan, and schematic cross section of the Kakkonda geothermal systems (modified after Doi et al., 1998). Well WD-1a encountered the boundary between the hydrothermalconvection and heat-conduction zones at a depth of $3100 \mathrm{~m}$ (Doi et al., 1998). This figure will be published by Saishu et al. (2014).

Acoustic and electrical borehole imaging tools can be used to determine the orientations of in situ principal stresses (through observations of breakouts and drilling-induced tensile cracks) as well as the distribution, orientation, and apparent apertures of preexisting natural fractures and faults. Image logs so acquired should be augmented with density logs to determine the vertical (overburden) stress, temperaturepressure-flow meter logs to identify preexisting permeable fractures and other fluid loss zones, and $P$ wave velocity logs to allow for in situ estimation of rock strength. The latter estimates are used to relate borehole breakout width to the magnitude of the greatest horizontal principal stress (SHmax) by using the magnitude of Shmin as measured during a minifrac test.

Below the brittle regime, preexisting fractures, if present, might have very low permeability and/or cohesive strength due to closure by plastic creep and sealing by secondary minerals. In such a case, it would be necessary to use higher fluid pressures to increase formation permeability through tensile failure. This could be augmented by extended circulation of cold fluids to lower the mean stress, creating a more pervasive, mixed-mode fracture network comprising both tensile and shear fractures. When a cold fluid is injected into a hightemperature rock, the fluid cools the rock locally around the injection borehole and fractures, and the cooling induces local shrinkage of the rock. Such shrinkage leads to a consider- able reduction in the fluid pressures required for fracture initiation at the borehole wall, fracture extension, and the opening of fracture networks.

\section{Geothermal exploration and monitoring of EGS reservoirs}

\subsection{Current status of technology}

Temperature mapping is an essential component of geophysical surveys for EGS development. The use of aeromagnetic survey data to map depth to the Curie temperature isotherm is the only known way to directly detect temperature at depth. A spectral analysis method has been developed that assumes a fractal distribution of crustal magnetization; this method has recently been used to estimate depth to the Curie temperature at a potential EGS site in a continental environment.

Gravity surveys can provide information about the density distributions in subsurface rocks such as the massive granitic bodies that form EGS reservoirs. Modern gravimeters, such as the new superconducting gravimeter, can detect weak signals caused by fluid flow in deep reservoirs.

Because hydrothermal systems normally produce diagnostic resistivity anomalies, subsurface images produced from 3-D magnetotelluric data have shown reasonable agreement with borehole resistivity logs. 
Monitoring of background seismic activity during the predevelopment phase of an EGS project is necessary in order to understand preexisting seismicity at the site. Hasegawa (2009), Imanishi et al. (2011a, b); Ma et al. (2012) and Schwartz and Rokosky (2007) showed various characteristics of seismic events which occurred beyond the BDT.

\subsection{Technological challenges for detecting suitable targets and monitoring developed reservoirs}

Recently developed 3-D repeated aeromagnetic survey techniques might be useful for estimation of deep magnetic structures related to hot dry rocks.

Recent advances in gravity survey technology, especially the development of new superconducting gravimeters, allow for the detection of small changes in the gravity field that are caused by mass movements or the redistribution of fluids in geothermal reservoirs.

Resolution at depth is inherently low in surface magnetotelluric survey data. To increase resolution, high-resolution surveys (such as cross-hole or borehole-surface electromagnetic surveys) should be conducted close to the reservoir.

\subsection{Current understanding of induced seismicity associ- ated with fluid injection and production at an EGS}

The hypocenters of large induced seismic events are usually within the central region of the seismic cloud or near its boundary. The source radii are comparable to or smaller than those of the hypocentral cloud (Asanuma et al., 2005, 2011; Mukuhira et al., 2013), suggesting that the size of the rupture is restricted by the dimensions of stimulated zones in an EGS. Pore pressures determined at the time of occurrence of large induced events has shown that fractures were not critically stressed then (Asanuma et al., 2012; Mukuhira et al., 2013; Terakawa et al., 2012). The observation that many large induced events have occurred after shut-in and bleeding-off indicates that reservoir pressure or stress state is redistributed as a result of the cessation of fluid flow.

\subsection{Expectations of induced seismicity for JBBP}

The reservoir required to extract thermal energy in the order of $10 \mathrm{MW}$ would be of dimensions in the order of several hundred meters; seismic events of moment magnitude 4-5 can be caused. However, if the reservoir is connected to an existing fracture system above the BDT (JBBP type 1 reservoir), the risk of large induced seismic events increases.

\subsection{Challenges for prevention of large induced seismicity in and around the JBBP reservoirs}

Dynamic THMC modeling of the reservoir and surrounding zones of the JBBP reservoir presents a challenge. Investigation of methods of reservoir creation such that large induced events are suppressed should be undertaken by integrated geomechanical modeling that deals with all of these factors.

\section{Engineering development}

\subsection{Current status of related technologies}

JBBP reservoirs will be created at depths of $3-5 \mathrm{~km}$ where formation temperatures are $350-500^{\circ} \mathrm{C}$ and formation pressures are 30-50 MPa. Experience gained during the drilling of well WD-1a at the Kakkonda geothermal field (Muraoka et al., 1998) suggests that fluids of high salinity and $\mathrm{HCl}$ content may be present. Functioning in conditions such as these is beyond the capability of most currently available off-theshelf technology.

\subsubsection{Current status of drilling and well completion technology}

1. The top drive system (TDS), which can continuously cool a borehole, enables penetration of rock masses at temperatures exceeding $500^{\circ} \mathrm{C}$ at Kakkonda (Saito et al., 1998).

2. In the IDDP (Iceland Deep Drilling Project), the drilling was delayed because of thermal cracking, hole collapse, and magma quenching to glass near/inside the magma body. Magma has also been intersected during drilling of injection well KS-13 in Hawaii (Teplow et al., 2009).

3. Well design may need to be revised to deal with supercritical fluids - in particular, to avoid steam explosions in the casing annulus by $\mathrm{HCl}, \mathrm{H}_{2} \mathrm{~S}, \mathrm{CO}_{2}$, and possibly HF. Recent corrosion and scaling experiments by IDDP-1 and the Salton Sea Project indicate that INCONEL $囚 a l l o y ~ 625$, titanium grade 7 and Beta-C titanium casing performed well (Ragnarsdóttir, 2013; Love et al., 1988).

4. Collection and recovery of spot-core samples from a high-temperature environment can be problematic (e.g., Lutz et al., 2012). An alternative approach is to use a hybrid drilling rig that can switch from rotary drilling to continuous wireline coring (e.g., Furry et al., 1996). Successful coring was achieved at high temperatures in IDDP wells by using a corer provided by Alister Skinner.

5. The cement commonly used to set casing can withstand temperatures up to about $400^{\circ} \mathrm{C}$. For the WD-1a well, casing was cemented at a formation temperature of around $360^{\circ} \mathrm{C}$ (Saito et al., 1998). Halliburton is developing a high-temperature cement (ThermaLock ${ }^{\mathrm{TM}}$ ) that can be used at formation temperatures up to $538^{\circ} \mathrm{C}$.

6. A bentonite- and water-based, low-solids, low-density mud was used with a high-temperature dispersant (G500S) in the Kakkonda WD-1a well. Telnite Co., Ltd. 
(Tokyo, Japan) now provides a Hypergel/G-500S hightemperature mud system. M-I SWACO (part of the Schlumberger group) can also provide high-temperature water-based muds usable at temperatures above $260{ }^{\circ} \mathrm{C}$.

7. A research and development project funded by the US Department of Energy to develop a high-temperature $\left(300^{\circ} \mathrm{C}\right)$ directional drilling system is being undertaken by Baker Hughes.

\subsubsection{Expectations for drilling and well completion for JBBP}

1. The borehole will need to be effectively cooled to below $160{ }^{\circ} \mathrm{C}$ during normal TDS drilling operations. Casing and cementing under extreme high temperature subsurface conditions should be possible if cooling of the borehole during TDS drilling is sufficient.

2. There will be risk of the buckling or breaking of casing pipe and the destruction of the cement sheath in response to the thermal stress induced by injection during the circulation of cool liquid into the high-temperature borehole. Corrosion of the casing pipe and wellhead may also occur.

3. Drilling of a highly deviated borehole into the BDT to create subvertical reservoirs of sufficient thermal capacity will be difficult.

\subsubsection{Current status of stimulation and injection technology}

1. Many EGS reservoirs have been created by full-hole pressurization, either by pressurizing the entire openhole section (Häring et al., 2008), or by isolating the open-hole section using casing packers.

2. The maximum operating temperature of the Halliburton RTTS $₫$ tool and inflatable packers is $180-190^{\circ} \mathrm{C}$. An alternative for zonal isolation during reservoir stimulation is the use of chemical diverters, which have been successfully deployed by the Newberry EGS project in Oregon, USA (e.g., Petty et al., 2013).

3. Multistage hydraulic fracturing equipment has been deployed in recent shale gas developments in North America, although in a relatively low-temperature environment. The stability and behavior of fracturing fluids and proppants under high-temperature conditions are poorly understood.

\subsubsection{Expectations for stimulation and injection for JBBP}

1. Multilevel stimulation to investigate changes in the response of the BDT rock mass with increasing depth should be undertaken within JBBP. A multilevel fracture system would be expected to increase the extent of fracturing for heat exchange. However, no packers that can be used under conditions expected in the BDT are currently commercially available.

\subsubsection{Current status of logging and sampling technology}

1. Most of the logging tools used in the oil industry can be operated at temperatures up to $175^{\circ} \mathrm{C}$. Some hightemperature (HT) pressure-temperature-spinner (PTS) tools can be used in memory mode at $400{ }^{\circ} \mathrm{C}$ on a slickline, whereas temperature, televiewer, and spectral gamma tools can be operated at up to $300{ }^{\circ} \mathrm{C}$ on a wireline. The maximum operating temperature for $\mathrm{HT}$ logging-while-drilling (LWD) tools is $230^{\circ} \mathrm{C}$.

2. The maximum operating temperature for a standard seven-core wireline cable is $315^{\circ} \mathrm{C}$; a slickline cable can be used at temperatures exceeding $400^{\circ} \mathrm{C}$.

3. The ICDP (International Continental Scientific Drilling Program) provides online monitoring of gas (OLGA) during drilling to extract and analyze gases $\left(\mathrm{N}_{2}, \mathrm{O}_{2}\right.$, $\mathrm{CO}_{2}, \mathrm{CH}_{4}, \mathrm{Ar}, \mathrm{He}, \mathrm{H}_{2}, \mathrm{C}_{1}-\mathrm{C}_{4},{ }^{222} \mathrm{Rn}$ ) from the circulating drilling mud. This technique has been successfully used in several ICDP projects (San Andreas Fault Observatory at Depth; Unzen, Japan) and IODP (International Ocean Discovery Program) riser drilling expeditions (e.g., Expedition 319) (e.g., Erzinger et al., 2006).

4. A downhole sampler was developed by Lysne et al. (1997) and by NEDO (New Energy and Industrial Technology Development Organization) (Sato et al., 2002). Thermochem Energy Consulting \& Chemical Testing has continued with the development of a twophase high-temperature (to $400{ }^{\circ} \mathrm{C}$ ) downhole sampler.

5. Metal-coated optic fiber designed for industrial and telecommunications use is thermostable up to $600{ }^{\circ} \mathrm{C}$, although cable length is limited to several tens of meters.

6. Most commercially available high-temperature electronic apparati, fabricated with silicon-on-insulator (SOI) technology, are limited to a maximum operating temperature of $225^{\circ} \mathrm{C}$ (a few to $300{ }^{\circ} \mathrm{C}$ ).

7. Wider band gap (WBG) materials such as silicon carbide ( $\mathrm{SiC})$ must be utilized for the fabrication of HT sensors and circuits (Azevedo et al., 2007).

\subsubsection{Expectations for logging and sampling for JBBP}

1. It will be possible to collect information about the BDT rock mass by LWD, although there are risks of thermal damage to downhole tools. 
2. Most of the existing logging tools can be run during or immediately after periods of circulation, at which times the borehole temperature will not have returned to its initial state.

3. Although operating times will be restricted, PTS tools can be used in memory mode during the stimulation and circulation phases. For thermal power monitoring, pressure and temperature tools will need to access the well for the full range of expected temperatures and pressures.

\subsubsection{Current status of technology for EGS reservoir maintenance}

1. Reservoir productivity is maintained by injection, pressure build-up, and stimulation.

2. Scaling is avoided via the acid treatment of injection fluids.

3. Scaling within heat exchange apparatus has been observed at Soultz (Scheiber et al., 2012).

\subsubsection{Expectations for maintenance of the JBBP reservoir}

1. The solubility of quartz will change drastically in the BDT, causing channeling and shortcut flow paths as a result of the solution and precipitation of quartz within the JBBP reservoir.

\subsection{Technology developments required for JBBP}

1. Drilling technologies: The risks and costs of drilling and well completion should be reduced as much as possible. Methods of well completion and materials used for casing and cementing that will allow long-term production and injection for JBBP reservoirs should be investigated. Coring equipment and operations should be developed that overcome the inadequate downhole cooling during coring operations.

2. Monitoring technology: fiber optic distributed sensing (e.g., distributed temperature sensing (DTS) + distributed acoustic sensing (DAS)) should be used to monitor and evaluate the stimulation treatment. Technologies to delineate the structure of the fracture system and the distribution of permeability should be developed. New survey methods (e.g., surface-borehole combination) and inversion theories (e.g., focused inversion) will be useful in identifying drilling targets and monitoring JBBP reservoirs. Highly sophisticated tracer methods (e.g., smart tracer) in combination with 3-D/4-D inversion theory have promise for reservoir monitoring.
3. Reservoir creation and maintenance technology: the use of proppants and appropriate fracturing/stimulation liquids should be investigated. Technologies that enable the avoidance or control of channeling and shortcut flow paths is of critical importance for sustainable production.

4. Zonal isolation technology: technology to isolate openhole sections at formation temperatures of up to $450^{\circ} \mathrm{C}$ should be developed to allow for the creation of multilevel thermally productive reservoirs.

5. Logging and borehole testing technologies: hightemperature logging tools that can operate at $450{ }^{\circ} \mathrm{C}$ are needed to understand the properties of the beyondbrittle rock mass and fracture system. A technique to measure or estimate in situ stress at beyond-brittle depths is of critical importance in the JBBP.

\section{Contribution of JBBP to Earth sciences}

The JBBP will directly contribute to a broad range of earth science disciplines. We expect that the information so derived from core analyses and bore hole tests can be effectively used to improve our understanding of phenomena such as dehydration/degassing of magmas, global hydrogeology in the Earth's crust, and the processes by which hydrothermal convection/conduction zones can be created. Laboratory tests on fracturing in rock specimens at high temperatures and pressures as well as the testing and monitoring of deep boreholes can provide information on the dynamic response and stress state of the rock mass beyond the BDT, which will lead to improved scientific understanding and interpretation of the mechanics of earthquakes at depth. New exploration technologies applied to identify the BDT will contribute to our ability to determine the thermal and structural characteristics of phenomena such as volcanoes and seismogenic zones in the Earth's crust.

\section{Roadmap and implementation plan}

Two-and-a-half years of lead time might be required before submission of a full drilling proposal to ICDP (Fig. 3). This lead time will be used to further our scientific understanding of the beyond-brittle rock mass, develop the new technologies, undertake surveys of possible sites, and develop a drill program and contingency plans.

A number of current geothermal projects target supercritical fluids in shallow, still-hot, molten igneous intrusions in young volcanic rocks along plate boundaries and at hot spots. These include established geothermal fields in Iceland, New Zealand, the Philippines, Indonesia, Italy, and the United States. International collaboration, particularly with ICDP high-temperature geothermal projects worldwide, is of 


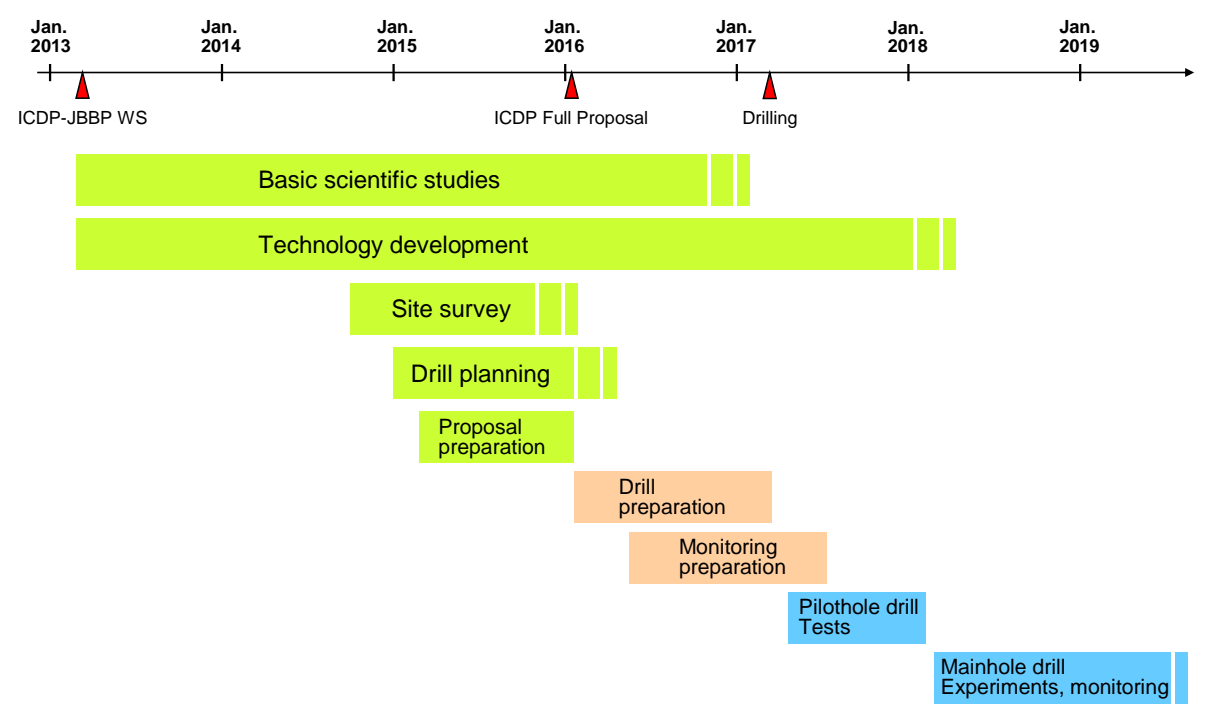

Figure 3. Roadmap for the development of the full JBBP proposal and subsequent drilling.

critical importance for success of the JBBP, as it will allow for the sharing of scientific knowledge and technology.

Acknowledgements. The core team of the JBBP would like to acknowledge ICDP and Tohoku University for their support in holding the workshop.

Edited by: T. Wiersberg

Reviewed by: one anonymous referee

\section{References}

Asanuma, H., Nozaki, H., Niitsuma, H., and Wyborn, D.: Interpretation of microseismic events with larger magnitude collected at Cooper Basin, Australia, Geoth. Res. T., 29, 87-91, 2005.

Asanuma, H., Mitsumori, S., Adachi, M., Saeki, K., Aoyama, K., Ozeki, H., Mukuhira, Y., and Niitsuma, H.: Characteristics of microearthquakes at Yanaizu-Nishiyama geothermal field, Geoth. Res. T., 35, 989-994, 2011.

Asanuma, H., Mitsumori, S., Adachi, M., Saeki, K., Aoyama, K., and Ozeki, H.: Estimation of stress state at Yanaizu-Nishiyama geothermal field using microseismic multiplets, Geoth. Res. T., 36, 989-994, 2012.

Azevedo, R., Jones, D., Jog, A., Jamshidi, B., Myers, D., Chen, L., Fu, X., Mehregany, M., Wijesundara, M., and Pisano, A.: A SiC MEMS resonant strain sensor for harsh environment applications, IEEE Sens. J., 7, 568-576, 2007.

Coumou, D., Driesner, T., and Heinrich, C. A.: The structure and dynamics of mid-ocean ridge hydrothermal systems, Science, 321, 1825-1828, 2008a.

Coumou, D., Driesner, T., and Heinrich, C. A.: Heat transport at boiling, near-critical, conditions, Geofluids, 8, 208-215, 2008b.

Doi, N., Kato, O., Ikeuchi, K., Komatsu, R., Miyazaki, S.-I., Akaku, K., and Uchida, T.: Genesis of the plutonic-hydrothermal system around quaternary granite in the Kakkonda geothermal system, Japan, Geothermics, 27, 663-690, 1998.
Erzinger, J., Wiersberg, T., and Zimmer, M.: Real-time mud gas logging and sampling during drilling, Geofluids, 6, 225-233, 2006.

Furry, S., Gunderson, R., and Dobson, P.: Slim-hole exploration in North Sumatra, Indonesia, Proc. Slimhole Technology Workshop, Sandia National Laboratories and the Geothermal Resources Council, NV, 22-24 July, 1996.

Häring, M. O., Schanz, U., Ladner, F., and Dyer, B.: Characterization of the Basel-1 enhanced geothermal system, Geothermics, 37, 469-495, 2008.

Hasegawa, A., Nakajima, J., Uchida, N., Okada, T., Zhao, D., Matsuzawa, T., and Umino, N.: Plate subduction, and generation of earthquakes and magmas in Japan as inferred from seismic observations: An overview, Gondwana Res., 16, 370-400, 2009.

Hayba, D. O. and Ingebritsen, S. E.: Multiphase groundwater flow near cooling plutons, J. Geophys. Res. 102, 12235-12252, 1997.

Imanishi, K., Kuwahara, Y., Takeda, T., Mizuno, T., Ito, H., Ito, K., Wada, H., and Haryu, Y.: Depth dependent stress field in and around the Atotsugawa fault, central Japan, deduced from microearthquake focal mechanisms: Evidence for localized aseismic deformation in the downward extension of the fault, J. Geophys. Res., 116, B01305, doi:10.1029/2010JB007900, 2011 a.

Imanishi, K., Takeda, N., Kuwahara, Y., and Koizumi, N.: Enhanced detection capability of non volcanic tremor using a 3-level vertical seismic array network, VAnet, in southwest Japan, Geophys. Res. Lett., 38, L20305, doi:10.1029/2011GL049071, 2011b.

Kaieda, H., Ito, H., Kiho, K., Suzuki, K., Suenaga, H., and Shin, K.: Review of the Ogachi HDR Project in Japan, Proceedings of the World Geothermal Congress 2005, 2005.

Love, W., Cron, C., and Holligan, D.: The use of Beta-C titanium for downhole production casing in geothermal wells, Geoth. Res. T., 12, 49-53, 1988.

Lutz, S. J., Walters, M., Pistone, S., and Moore, J. N.: New insights into the high-temperature reservoir, Northwest Geysers, Geoth. Res. T., 36, 907-916, 2012.

Lysne, P., Koenig, B., Hirtz, P., Normann, R., and Henfling, J.: Subsurface steam sampling in Geysers wells, Geoth. Res. T., 21, 629-633, 1997. 
Ma, K.-F., Lin, Y.-Y., Lee, S.-J., Mori, J., and Brodsky, E. E.: Isotropic Events Observed with a Borehole Array in the Chelungpu Fault Zone, Taiwan, Science, 337, 459, doi:10.1126/science.1222119, 2012.

Majer, E., Baria, R., Stark, M., Oates, S., Bommer, J., Smith, B., and Asanuma, H.: Induced seismicity associated with enhanced geothermal systems, Geothermics, 36, 185-222, 2007.

Mukuhira, Y., Asanuma, H., Niitsuma, H., and Häring, M.: Characteristics of large-magnitude microseismic events recorded during and after stimulation of a geothermal reservoir at Basel, Switzerland, Geothermics, 45, 1-17, 2013.

Muraoka, H., Uchida, T., Sasada, M., Yagi, M., Akaku, K., Sasaki, M., Yasukawa, K., Miyazaki, S., Doi, N., Saito, S., Sato, K., and Tanaka, S.: Deep geothermal resources survey program: igneous, metamorphic and hydrothermal processes in a well encountering $500^{\circ} \mathrm{C}$ at $3729 \mathrm{~m}$ depth, Kakkonda, Japan, Geothermics, 27 , 507-534, 1998.

Petty, S., Nordin, Y., Glassley, W., Cladouhos, T. T., and Swyer, M.: Improving geothermal project economics with multi-zone stimulation: Results from the Newberry Volcano EGS demonstration, Proc. 38th Workshop on Geoth. Reservoir Eng., Stanford U. CA, 11-13 February, SGP-TR-198, 2013.

Ragnarsdóttir, K. R.: Corrosion Experiments in Dry Superheated Steam from IDDP-1, M.Sc. thesis, Faculty of Industrial Engineering, Mechanical Engineering and Computer Science, University of Iceland, 2013.

Saishu, H., Okamoto, A., and Tsuchiya, N.: The significance of silica precipitation on the permeable/impermeable boundary within the Earth's crust, Terra Nova, in press, 2014.

Saito, S., Sakuma, S., and Uchida, T.: Drilling procedures, techniques and test results for a $3.7 \mathrm{~km}$ deep, $500{ }^{\circ} \mathrm{C}$ exploration well, Kakkonda, Japan, Geothermics, 27, 571-590, 1998.

Sato, M., Okabe, T., Nakata, H., Sleet, P., Twose, C., Hirtz, P., Kasagi, T., Goko, K., and Kondo, T.: Development of a high temperature borehole fluid sample and its field experiment in the Ogiri geothermal field, Japan, Geoth. Res. T., 26, 357-360, 2002.
Scheiber, J., Nitschke, F., Seibt, A., and Genter, A.: Geochemical and mineralogical monitoring of the geothermal power plant in Soultz-Sous-Forets (France), Proc. 37th Workshop on Geoth. Reservoir Eng., Stanford U. CA, 30 January-1 February, SGPTR-194, 2012.

Schwartz, S. Y. and Rokosky, J. M.: Slow slip events and seismic tremor at circum-Pacific subduction zones, Rev. Geophys., 45, 1-32, 2007.

Tenma, N., Yamagachi, T., Okabe, T., and Zyvolosky, G.: Estimation of the Characteristics of the Hijiori Reservoir at the HDR Test Site during a Long-Term Circulation Test, Term 2 and Term 3, Geoth. Res. T., 28, 245-249, 2004.

Teplow, W., Marsh, B., Hulen, J., Spielman, P., Kaleikini, M., Fitch, D., and Rickard, W.: Dacite melt at the Puna Geothermal Ventures wellfield, Big Island of Hawaii, Geoth. Res. T., 33, 989994, 2009.

Terakawa, T., Miller, S. A., and Deichmann, N.: High fluid pressure and triggered earthquakes in the enhanced geothermal system in Basel, Switzerland, J. Geophys. Res., 117, B07305, doi:10.1029/2011JB008980, 2012.

Weis, P., Driesner, T., and Heinrich, C. A.: Porphyry-copper ore shells form at stable pressure-temperature fronts within dynamic fluid plumes, Science, 338, 1613-1616, 2012.

\section{Web references}

US Department of Energy, Geothermal Technologies Office (http://www4.eere.energy.gov/geothermal/projects/140)

Schlumberger (http://www.slb.com/services/drilling/ directional_drilling/powerdrive_family.aspx) 